\title{
A One Pot Photochemical Method for the Generation of Functionalized Aminocyclopentanes
}

Madison J. Sowden; James L. Collins III, Daryl Staveness, Corey R. J. Stephenson*

Department of Chemistry, University of Michigan, Ann Arbor, MI 48109, USA.

\section{Keywords}

Photochemistry, Cycloaddition, Cyclopropylimine; cyclopentylamine; visible light; radical chemistry, continuous flow processing

\section{Abstract}

Detailed herein is the development of a photochemical intermolecular formal [3+2] cycloaddition between cyclopropylimines and substituted alkenes to generate cyclopentylimines. The Schiff base auxiliary of the cyclopropylimine was designed to enable a masked $\mathrm{N}$-centered radical approach in which the requisite open-shell character was achieved upon excitation with violet light. The cycloaddition products were directly converted to $N$-functionalized aminocyclopentanes via $N$-acylation and solvolysis, thus offering a threestep, one-pot procedure for the production of diversely-substituted aminocyclopentanes. The photochemical component of this reaction sequence was demonstrated to operate in continuous flow and was amenable to gram-scale production.

\section{Introduction}

Cyclopentanes are common building blocks often found in various natural products, pharmaceuticals and agrochemicals. ${ }^{1,2}$ There have been many developed methodologies for the synthesis of cyclopentanes disclosed throughout the literature; however, typically these methodologies require the use of metals $^{3-7}$, high temperatures ${ }^{8}$ and/or extended 
reaction times. ${ }^{9}$ In recent years, single-electron processes (i.e. photoredox catalysis) have become more prevalent throughout the pharmaceutical and agrochemical industries, and have allowed improved access to chemical building blocks via unique reactive intermediates. ${ }^{10}$ In 2012, Zheng and co-workers provided a photochemical [3+2] cycloaddition strategy for the synthesis of cyclopentane products (Figure 1A). ${ }^{11}$ Following this report, in 2016, Yoon and co-workers reported an enantioselective Lewis acid photocatalytic [3+2] cycloaddition for the synthesis of aryl cyclopentanes. ${ }^{12}$ Both of these reports allowed for milder conditions to be used for the synthesis of these important building blocks, but in both cases ruthenium photocatalysts were needed to access the desired reactive intermediates. In 2018, Lin and co-workers disclosed a titanium catalyzed [3+2] cycloaddition for the synthesis of cyclopentanes. ${ }^{13}$ While highly selective and efficient, the reaction requires a complex titanium catalyst and stoichiometric manganese.

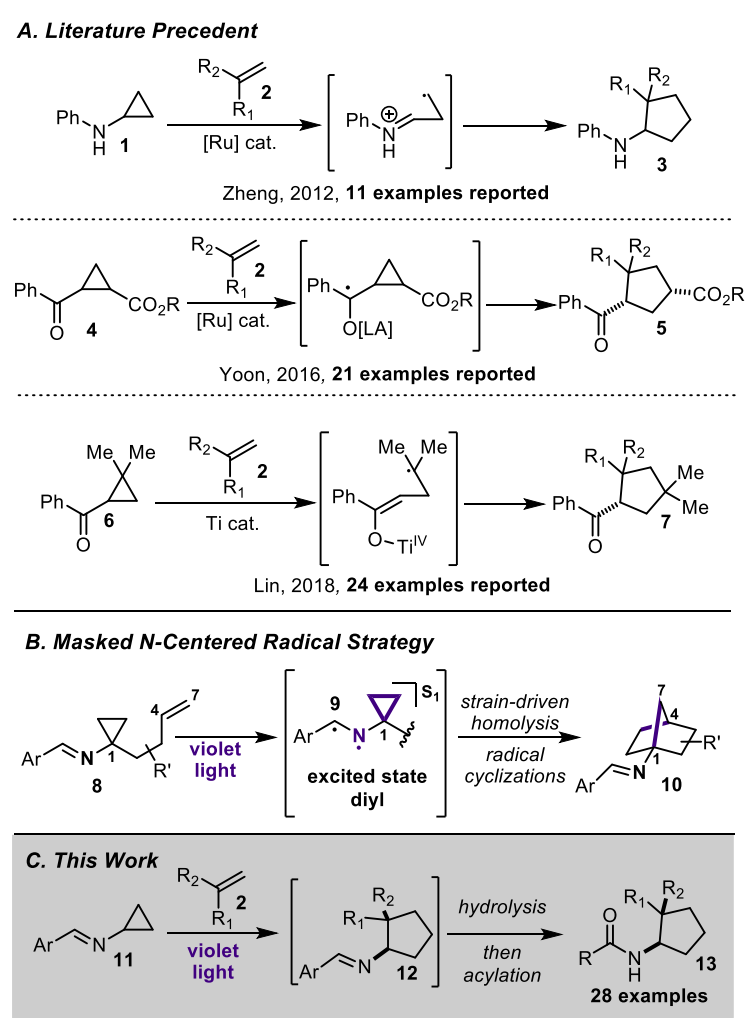

Figure 1. Prior art and this work. 
We envisioned gaining metal-free access to similar reactive intermediates through the use of imine photochemistry. Our laboratory recently disclosed a formal strain-driven intramolecular [3+2] cycloaddition for the synthesis of 1-aminonorbornanes (1aminoNBs)(Figure 1B). ${ }^{14}$ This methodology exploited visible-light imine photochemistry to generate an excited state diyl, which in turn initiated strain-driven fragmentation of a cyclopropane ring and serial cyclization reactions to generate the final 1-aminoNB product.

Herein, we report the synthesis of various cyclopentylamine products via a straindriven intermolecular formal [3+2] cycloaddition (Figure 1C). Similar to our previously disclosed intramolecular [3+2] cycloaddition, treatment of cyclopropylimine (11) with violet light results in the formation of excited state diyl (14) (Figure 2). The $\mathrm{N}$-centered radical initiates the strain-driven homolysis of the cyclopropane ring. The newly generated $\beta$ iminium radical intermediate 15 then undergoes an initial intermolecular 5-exo-trig cyclization in the presence of an alkene, followed by an intramolecular 5-exo-trig cyclization resulting in the formation of cyclopentane ring 17 . Notably, both radicals are then terminated via recombination, to regenerate the $\mathrm{C}-\mathrm{N}$ double bond of the Schiff base, and afford the desired Schiff base-protected aminocyclopentane 12. With this newly developed methodology, we are able to not only generate these products under milder reaction conditions, but we are afforded the capability to build chemical complexity more rapidly, while also garnering access to more complex 3-D chemical space. Significantly, this methodology allows for the initial [3+2] cycloaddition, hydrolysis of the subsequent Schiff base product, and $\mathrm{N}$-functionalization of the free cyclopentylamine all in one-pot.

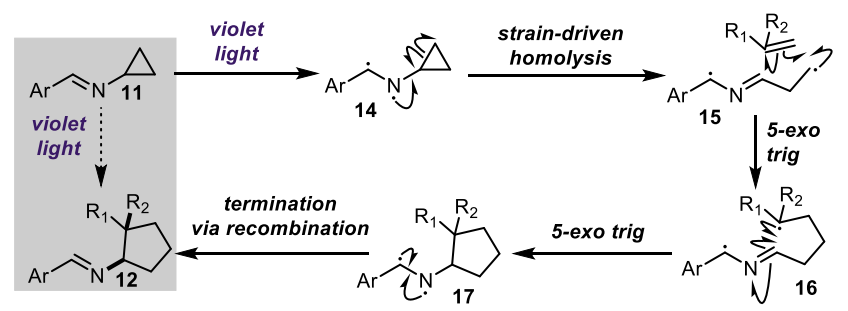

Figure 2. Proposed mechanism for intermolecular formal [3+2] cycloaddition. 


\section{Results}

In order to translate this reactivity into an intermolecular setting, there are notable challenges that must be overcome. Chief among them, the key intermediate arising from ring opening of the cyclopropane must be sufficiently long lived to react with an alkene equivalent. In order to intercept this radical we anticipated that highly reactive alkenes would be required for these reactions. The use of such alkenes could lead to problems associated with polymer formation which may be difficult to suppress. These considerations guided our development of the reaction.

We commenced the assessment of our intermolecular [3+2] sequence with reaction optimization. The cyclopropylimine Schiff base starting material was easily prepared on multi-gram scale via a condensation reaction between commercially available cyclopropylamine and 4-nitrobenzaldehyde. ${ }^{15}$ With large quantities of starting material in hand reaction optimization was undertaken. As there was a desire for this reaction to be amenable to flow chemistry, it was necessary for this sequence to be optimized so that the formation of polymeric materials and other solids were minimized/eliminated. 


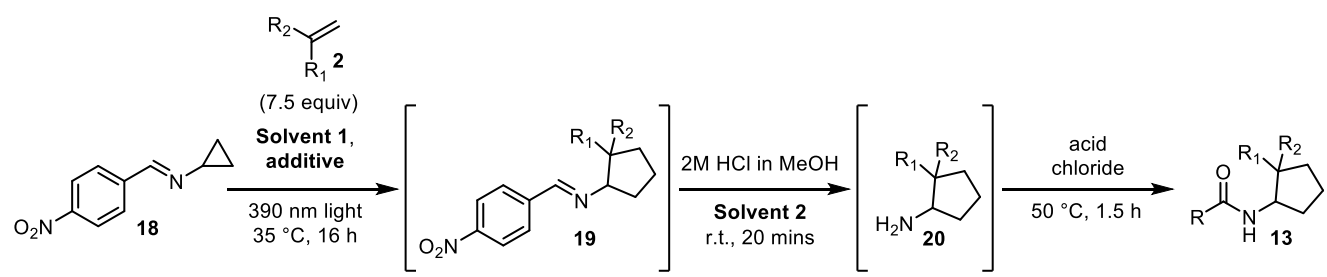

\begin{tabular}{|c|c|c|c|c|c|}
\hline Trial & Solvent 1 & Additive & $\begin{array}{c}\text { Additive } \\
\text { Loading }\end{array}$ & Solvent 2 & Isolated Yield \\
\hline 1 & EtOAc & BHT & $1 \mathrm{~mol} \%$ & $\mathrm{CH}_{2} \mathrm{Cl}_{2}$ & $63 \%$ \\
2 & EtOAc & DTDP & $1 \mathrm{~mol} \%$ & $\mathrm{CH}_{2} \mathrm{Cl}_{2}$ & $56 \%$ \\
3 & EtOAc & Irganox & $1 \mathrm{~mol} \%$ & $\mathrm{CH}_{2} \mathrm{Cl}_{2}$ & $64 \%$ \\
4 & EtOAc & $22 \mathrm{M} 46$ & $1 \mathrm{~mol} \%$ & $\mathrm{CH}_{2} \mathrm{Cl}_{2}$ & $63 \%$ \\
5 & EtOAc & Aldrithiol & $1 \mathrm{~mol} \%$ & $\mathrm{CH}_{2} \mathrm{Cl}_{2}$ & $65 \%$ \\
6 & EtOAc & TMQ & $1 \mathrm{~mol} \%$ & $\mathrm{CH}_{2} \mathrm{Cl}_{2}$ & $62 \%$ \\
7 & EtOAc & Allopurinol & $1 \mathrm{~mol} \%$ & $\mathrm{CH}_{2} \mathrm{Cl}_{2}$ & $57 \%$ \\
8 & EtOAc & - & - & $\mathrm{EtOAc}^{2}$ & $60 \%$ \\
\hline 9 & EtOAc & Aldrithiol & $10 \mathrm{~mol} \%$ & $\mathrm{EtOAc}^{2}$ & $68 \%$ \\
10 & PhMe & Aldrithiol & $10 \mathrm{~mol} \%$ & $\mathrm{PhMe}^{2}$ & $38 \%$ \\
11 & CH $\mathrm{Pl}_{2}$ & Aldrithiol & $10 \mathrm{~mol} \%$ & $\mathrm{CH}_{2} \mathrm{Cl}_{2}$ & $56 \%$ \\
12 & EtOAc & Aldrithiol & $10 \mathrm{~mol} \%$ & $\mathrm{CH}_{2} \mathrm{Cl}_{2}$ & $67 \%$ \\
\hline 13 & EtOAc & Aldrithiol & $50 \mathrm{~mol} \%$ & $\mathrm{CH}_{2} \mathrm{Cl}_{2}$ & $66 \%$ \\
\hline
\end{tabular}

Figure 3. Reaction optimization studies. Optimization reactions conducted on $0.4 \mathrm{~mol}$ scale using $390 \mathrm{~nm}$ wavelength Kesil lamps.

Several optimization screens were undertaken (Figure 3), the first being an screen of polymer preventing additives used within industry (entries $1-7)^{16}$, the second was a screen of reaction solvent (entries 8-11) and the third a screen of additive loading (entries 12-13. From these studies it was found that the best conditions for the [3+2] component of the sequence utilized ethyl acetate as solvent 1,7.5 mol equivalents of substituted alkene and $1 \mathrm{~mol} \%$ of 2,2'-dipyridyl disulfide (Aldithiol) as a polymer suppressing additive. This mixture was then irradiated under $390 \mathrm{~nm}$ light at $35{ }^{\circ} \mathrm{C}$ for 16 hours before being diluted with dichloromethane (solvent 2) and hydrolyzed with $2 \mathrm{M} \mathrm{HCl}$ in $\mathrm{MeOH}$ at ambient temperature. The addition of dichloromethane before the $2 \mathrm{M} \mathrm{HCl}$ in $\mathrm{MeOH}$ to the reaction was found to reduce the amount of solid materials that crashed out upon addition of the acid. The final phase of the reaction sequence involves the addition of a substituted acid chloride to the reaction followed by heating. 
It could be envisaged that different patterns of substitution could be introduced at three different points of the reaction: 1) the alkene component could contain various patterns of substitution; 2) a variety of substituted acyl chlorides could be employed in the final phase of the reaction; or 3) the cyclopropylimine starting material could be substituted leading to further substitution on the cyclopentylamine ring. Investigations into reaction scope commenced with the exploration of substitution on the styrenyl component (Table 1). All of the substituted styrenes explored during this phase of the project were either commercially available or were easily generated via a Wittig olefination of the corresponding ketone. ${ }^{17}$ Neutral, electron-deficient, and electron-rich styrenyl systems were all tolerated by the reaction. The best yields were attained from the neutral and electron-deficient styrenes, while electron-donating substituents resulted in decreased yields. In the cases of the electron-rich styrenes larger quantities of solids were observed upon completion of the reaction and on work up, suggesting unidentified side reactions as a result of the altered electronics. 4-Vinylpyridine derived product 19a could not be hydrolyzed under standard conditions or at elevated temperatures. As such this compound was isolated as the Schiff base intermediate. Interestingly, attempts to isolate the Schiff base intermediate derived from 1,1 '-diphenyl ethylene during the optimization phase proved highly difficult due to the surprising instability of this compound towards common purification techniques.

Mono substituted styrenyl compounds (22a-f), symmetrically (22g-i) and unsymmetrically (22j-k) substituted 1,1-aryl alkenes as well as alpha alkyl styrenes $\mathbf{2} \mathbf{2} \mathbf{m}$ p) were all tolerated by the reaction. Both mono-substituted and unsymmetrically 1,1'-disubstituted alkenes led to $\sim 1: 1$ mixtures of diastereomers (anti:syn). Fortunately, the diastereomers are easily separable through re-crystallisation in which the anti-compounds crystallized preferentially (see x-ray of compound $22 p$ in Table 1), chromatography or via HPLC. Unfortunately, solely alkyl substituted alkenes, tetra and tri-substituted alkenes, and 1,2-di-substituted alkenes were not tolerated by the reaction (see SI for further details) either 
reacting negligibly or not at all during the 16 hours of irradiation. This lack of reactivity is likely a result of steric hinderance in the cases of the tetra and tri-substituted alkenes, and while in the case of the the 1,2-disubstituted alkenes and terminal olefins, a lack of difference electronic polarization is the assumed explanation for the loss of reactivity that is observed.

Of the non-aromatic alkenes tested in this reaction only 1-chloro acrylonitrile (22I) was successful. This result is in line with those observed in the aromatic series, with highly electron-deficient substrates performing best in the reaction sequence.

Table 1. Substituted alkene scope.

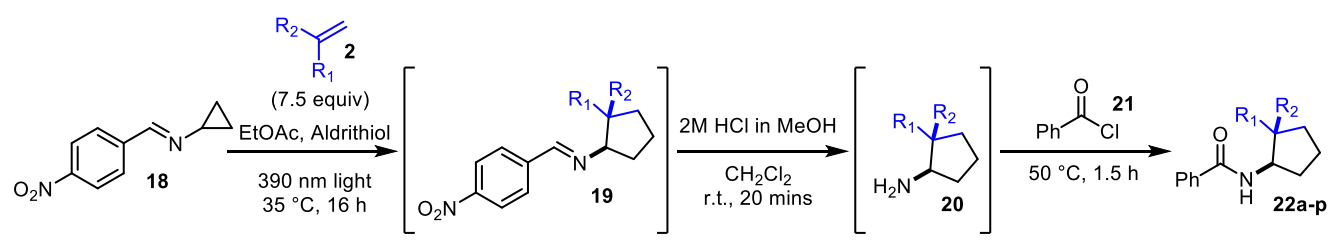

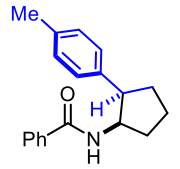

22a, $10 \%$

anti:syn $=1.0: 1.1$

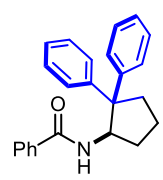

22g, $58 \%$

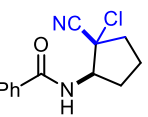

221, $88 \%$ anti:syn $=1.0: 1.1$

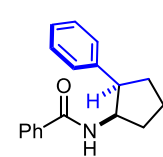

22b, $77 \%$

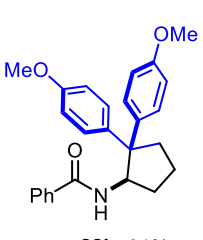

22h, $31 \%$

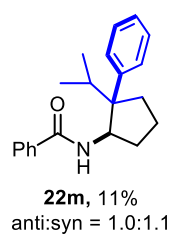

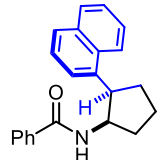

22c, $79 \%$

anti:syn $=1.0: 1.2$

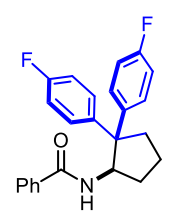

22i, $32 \%$

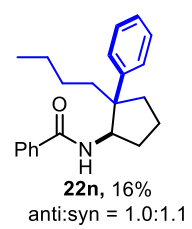

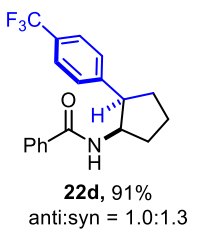
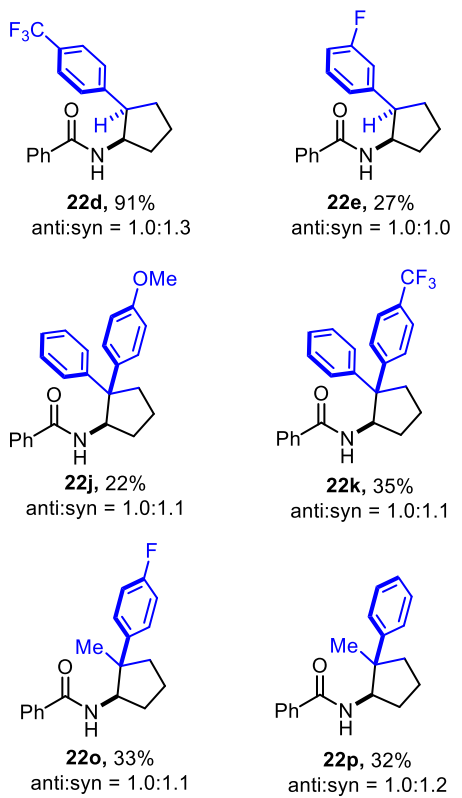
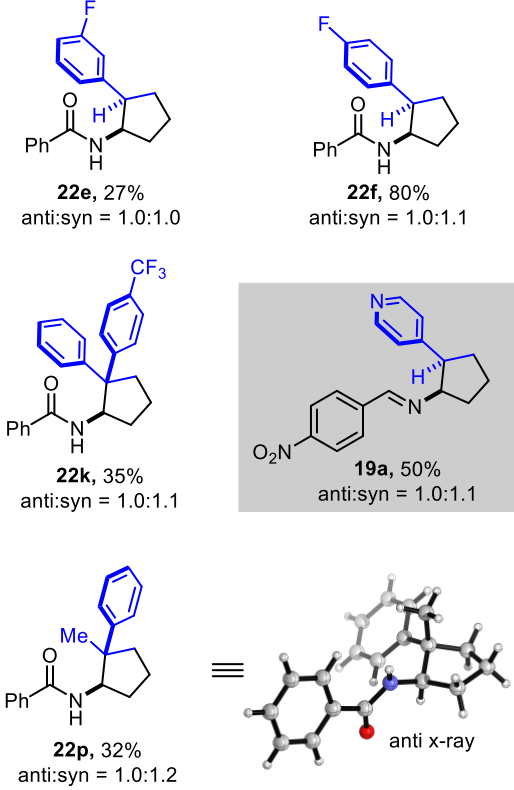

The scope for the acid chlorides was then explored (Table 2). Using 1,1-diphenyl ethylene as the alkene component of the reaction, a range of alkyl (26a, 26c, 26e), aromatic (26b, 26f-h) and heterocyclic (26d) acyl chlorides were tolerated. With the aromatic acyl chlorides, neutral, electron withdrawing and electron donating substitution patterns were all successful, again with electron withdrawing substituted compounds performing best. Alkyl 
substituted acyl chlorides necessitated slight modification to the reaction sequence. After hydrolysis, the material was concentrated under reduced pressure in order to remove excess $\mathrm{HCl}$ and methanol.

Table 2. Substituted acyl chloride scope.

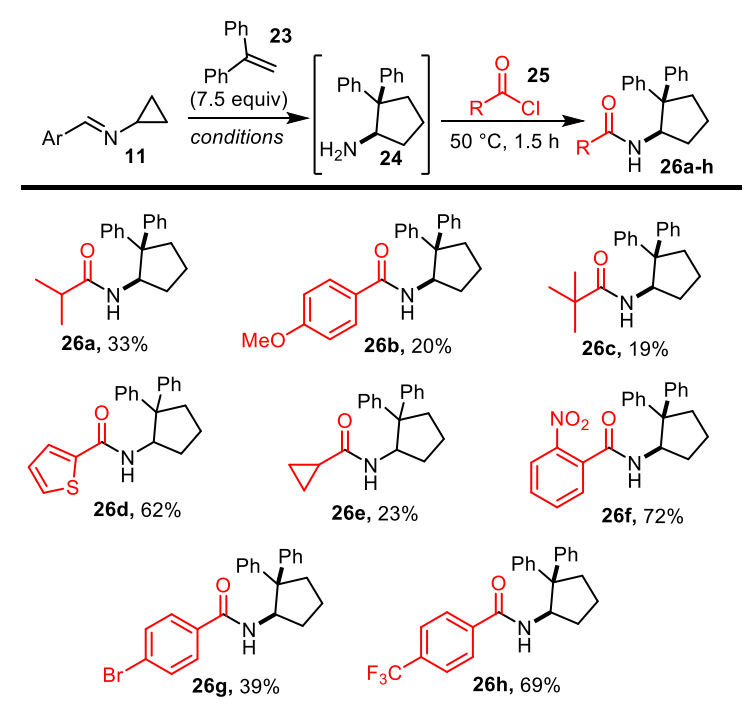

Conditions: EtOAc, DPS, $390 \mathrm{~nm}$ light, $35^{\circ} \mathrm{C}, 16 \mathrm{~h}$ then $2 \mathrm{M} \mathrm{HCl}$ in $\mathrm{MeOH}, \mathrm{CH}_{2} \mathrm{Cl}_{2}$, r.t. 20 mins. aafter hydrolysis the solvent is removed under reduced pressure.

The final facet of substrate scope exploration centered upon substitution on the cyclopropyl ring of the cyclopropylimine starting material. Having either phenyl (27) or methyl (31) substituents at the $\mathrm{C} 1$ position of the cyclopropylimine starting material resulted in the formation of the corresponding C1 substituted cyclopentylamine products (30 and 33) albeit in modest yields. The reaction is also tolerant of substitution at the $\mathrm{C} 2$ position of the cyclopropyl ring as is evidenced by dimethyl substituted compound 36 . Unfortunately, having a phenyl (37) substituent at the C2 position of the cyclopropylimine starting material appeared to shut down the reaction, this is presumably due to radical stabilization (39) at this site preventing/hindering further reactivity (Scheme 1). ${ }^{18}$ 


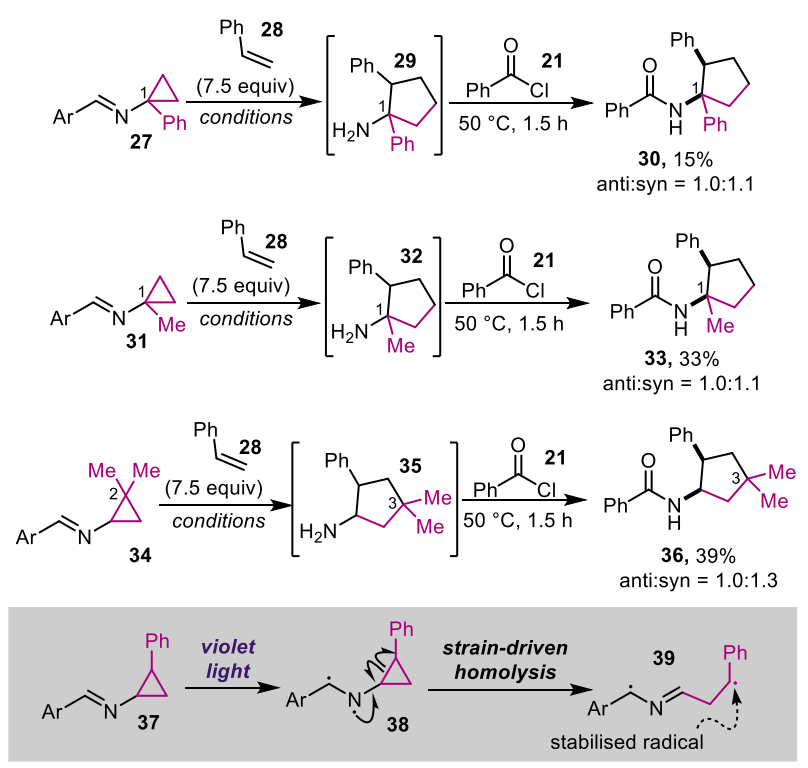

Scheme 1. Substituted cyclopropylimine scope. Conditions: EtOAc, DPS, $390 \mathrm{~nm}$ light, 35 ${ }^{\circ} \mathrm{C}, 16 \mathrm{~h}$ then $2 \mathrm{M} \mathrm{HCl}$ in $\mathrm{MeOH}, \mathrm{CH}_{2} \mathrm{Cl}_{2}$, r.t., 20 mins.

To further expand upon the utility of this reactivity, efforts to optimize the photochemical $[3+2]$ in flow were pursued. Upon optimization, it was found that the reaction mixture could be prepared similarly to that of the optimized batch conditions, as the only modifications were the addition of an extra 1.5 equivalents of styrene (9.0 equivs total) and a constant temperature of $50{ }^{\circ} \mathrm{C}$. After the mixture was degassed, a peristaltic pump was used to flow the mixture into the Uniqsis Photosyn flow reactor $(14 \mathrm{~mL}$ coil, $1.0 \mathrm{~mm} \mathrm{ID}, 1 / 16$ " OD HPFA tubing) and irradiating at $385 \mathrm{~nm}$. The time required for the [3+2] component of the reaction sequence was greatly diminished through the use of flow chemistry, with the reaction time reduced from 16 hours to between 55 minutes and 1 hour and 35 minutes (40 minutes residence time to 1 hour and 15 minute residence time). As a result of this reduction in time, the whole reaction sequence can now be run in a single day rather than over the course of two days. The yields attained in flow are comparable to those in batch and the reaction was also found to be scalable with compound $22 \mathrm{f}$ run on $1 \mathrm{gram}$ scale (Table 3 ). 
Table 3. Substrates accessed using flow conditions.
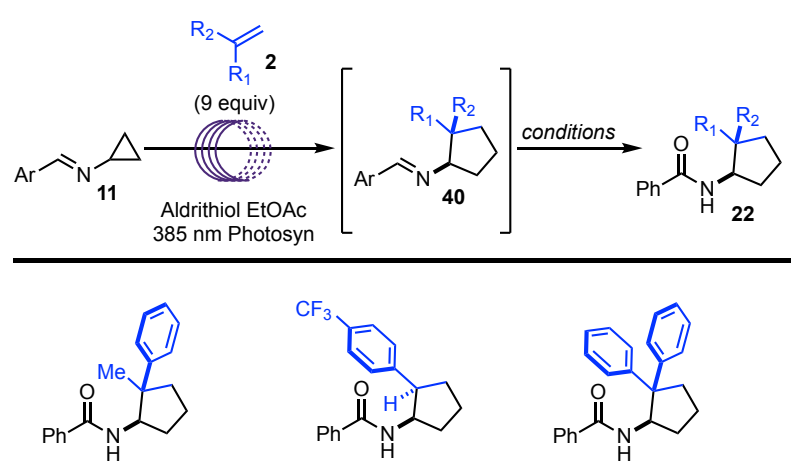

$22 p, 36 \%$

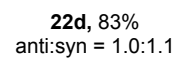

22g, $48 \%$
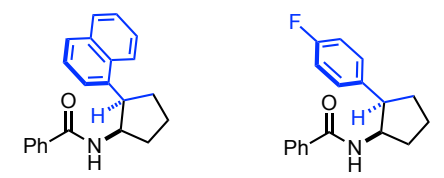

22c, 56\%
anti:syn $=1.0: 1.1$

22f, $77 \%$, $1 \mathrm{~g}$ scale $=60 \%$ anti:syn = 1.0:1.1
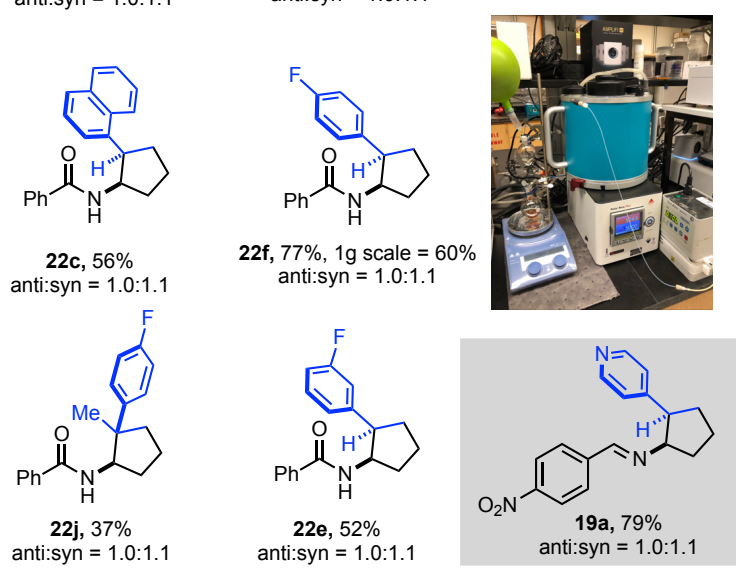

Conditions: $2 \mathrm{M} \mathrm{HCl}$ in $\mathrm{MeOH}, \mathrm{CH}_{2} \mathrm{Cl}_{2}$, r.t. 20 mins then benzoyl chloride $50{ }^{\circ} \mathrm{C}, 1.5$ hours.

\section{Conclusion}

This work expands the use of a masked $N$-centered radical strategy to generate highly functionalized cyclopentylamines via an intermolecular formal [3+2] cycloaddition. This modular three phase reaction sequence allows rapid one pot synthesis of complex cyclopentyl building blocks, readily scaled in continuous flow. This methodology lends itself to the rapid generation of biologically relevant molecules.

\section{Experimental Procedures}

For detailed experimental procedures and characterization data for all compounds and precursors presented above, see the Supporting Information. 
The authors acknowledge the financial support for this research from the NIH NIGMS (R01GM127774) and the University of Michigan. MJS was supported by the Australian Governments Endeavour Leadership Fellowship. DS was supported by a Postdoctoral Fellowship, PF-16-236-01-CDD, from the American Cancer Society. JLC was supported by the University of Michigan's Rackham Merit Fellowship.

\section{Author Information}

Corresponding author: crjsteph@umich.edu

\section{Declaration of Interests}

The authors declare no competing financial interests.

\section{Refences}

1. Douglas, J. J.; Sevrin, M. J.; Stephenson, C. R. J. Visible light photocatalysis: applications and new disconnections in the synthesis of pharmaceutical agents. Org. Process Res. Dev. 2016. 20(7): 1134-1147.

2. Kärkäs, M.; Porco, J.; Stephenson, C. R. J. Photochemical approaches to complex chemotypes: applications in natural product synthesis. Chem. Rev. 2016. 116: 96839747.

3. Azzena, U., Dettori, G., Lubinu, C., Mannu, A., Pisano, L. Reductive metalation of 1,2-diaryl-substituted ethenes: synthetic applications. Tetrahedron. 2005. 61: 86638668.

4. KC, S., Basnet, P., Thapa, S., Shrestha, B., Giri, R. Ni-Catalyzed Regioselective Dicarbofunctionalization of Unactivated Olefins by Tandem Cyclization/CrossCoupling and Application to the Concise Synthesis of Lignan Natural Products. J. Org. Chem. 2018. 83: 2920-2936. 
5. Zielinski, G. K., Majtczak, J., Gutowski, M., Grela, K. A Selective and Functional Group-Tolerant Ruthenium-Catalyzed Olefin Metathesis/Transfer Hydrogenation Tandem Sequence Using Formic Acid as Hydrogen Source. J. Org. Chem. 2018. 83: 2542-2553.

6. Clive, D. L. J., Wang, J. A Tin Hydride Designed To Facilitate Removal of Tin Species from Products of Stannane-Mediated Radical Reactions. J. Org. Chem. 2002. 67: 1192-1198.

7. Terada, Y., Arisawa, M., Nishida, A. Cycloisomerization Promoted by the Combination of a Ruthenium-Carbene Catalyst and Trimethylsilyl Vinyl Ether, and its Application in The Synthesis of Heterocyclic Compounds: 3-Methylene-2,3dihydroindoles and 3-Methylene-2,3-dihydrobenzofurans. Angew. Chem. Int. Ed. 2004. 43: 4063-4067.

8. Fruchey, E. R., Monks, B. M., Patterson, A. M., Cook, S. P. Palladium-Catalyzed Alkyne Insertion/Reduction Route to Trisubstituted Olefins. Org. Lett. 2013. 15: 43624365.

9. Zhou, X.; Ko, H. M.; Dong, G. Synthesis of bridged cyclopentane derivatives by catalytic decarbonylative cycloaddition of cyclobutanones and olefins. Angew. Chem. Int. Ed. 2016. 55: 13867-13871

10. Liu, G.; Shirley, M. E.; Van, K. N.; McFarlin, R. L.; Romo, D., Rapid assembly of complex cyclopentanes employing chiral, $\alpha, \beta$-unsaturated acylammonium intermediates. Nature Chemistry. 2013. 5: 1049-1057.

11. Maity, S., Zhu, M., Shinabery, R. S., Zheng, N. Intermolecular [3+2] Cycloaddition of Cyclopropylamines with Olefins by Visible-Light Photocatalysis. Angew. Chem. Int. Ed. 2012. 51: 222-226. 
12. Amador, A. G., Sherbrook, E. M., Yoon, T. P. Enantioselective Photocatalytic [3 + 2] Cycloadditions of Aryl Cyclopropyl Ketones. J. Am. Chem. Soc. 2016. 138: 47224725

13. Hao, W., Harenberg, J. H., Wu, X., MacMillan, S. N., Lin, S. Diastereo- and Enantioselective Formal [3+2] Cycloaddition of Cyclopropyl Ketones and Alkenes via Ti-Catalyzed Radical Redox Relay. J. Am. Chem. Soc. 2018. 140: 3514-3517

14. Staveness, D., Collins, J. L., McAtee, R. C., Stephenson, C. R. J. Exploiting Imine Photochemistry for Masked N-Centered Radical Reactivity. Angew. Chem. Int. Ed. 2019. 58: $19000-19006$

15. See supporting information.

16. Arvind Mafatial Group. Nocil Limited. (2010). Antioxidants and Antidegradants. http://www.nocil.com/Downloadfile/ETechnicalNote-Antioxidants-Dec2010.pdf

17. Schollkopf, U., Wittig, G. About triphenyl phosphine methylene as olefin-forming reagents. Chemische Berichte. 1954. 87: 1318-1330.

18. Walter, R. I., Substituent effects on the properties of stable aromatic free radicals. The criterion for non-Hammett behavior. J. Am. Chem. Soc. 1966. 88: 1923-1930. 